\title{
Automatic Lights ON/OFF System
}

\author{
PRADEEPAN.S ${ }^{1}$, VISHNU VARADHAN.V ${ }^{2}$, TAMIL SELVAN.A ${ }^{3}$,HARESHKUMAR.V ${ }^{4}$
}

UG STUDENTS $12 \cdot 314$

\author{
DEPARTMENT OF AGRICULTURE ENGINEERING
}

SRI SHAKTHI INSTITUTE OF ENGINEERING AND TECHNOLOGY

\begin{abstract}
In routine life the power utilization for electrical lights are more in the evenings when it is manually operated. The automatic lights on/off system will turn on the lights when the intensity of daylight is less and the lights will be turned off if the intensity of daylight is more. The intensity of daylight is sensed using the help of LDR sensor which send its sensed data to the power relay module which is an electrically operated switch. With improvement in technology, things are getting to be easier and simpler for everybody around the world. The Automatic light on/off system gives an answer for power utilization and saving which is accomplished by detecting the intensity of daylight utilizing the LDR sensors, integrated circuit (IC4093) and power relay module. Automation plays a vital job on the world's economy and in day-by-day experience of people.
\end{abstract}

Key words: LDR, IC4093, Power relay module, Automation.

\section{INTRODUCTION (Size 11, Times New roman)}

The power utilization of electrical lights will be reduced by using the automatic lights on/off system. It will also reduce the man-power involved in the operation of lights in public places, which will directly reduce the cost of operation. The power saved can be used usefully for other power needs. The power-production is directly or indirectly connected to the greenhouse gas emissions. which is reduced by this automatic lighting system.

\section{A. LDR (light dependent resistors)}

LDR (light dependent resistors) which is also referred as photoresistors. We used GL55 series LDR sensor for this automation of lighting. This resistor works on the principle of photo conductivity LDR s are more commonly used in electronic circuit designs where it is necessary to detect the intensity of the light and change the operation of the circuit dependent upon the light intensity level. when light falls with high intensity on the surface of light dependent resistors (LDR), then the material conductivity reduces and when the light falls on the surface has less intensity, then the conductivity increase. In our automation light on/off system the LDR s playing the major role. Because with the intensity of the day light the electric lights are turned on (or) turned off.

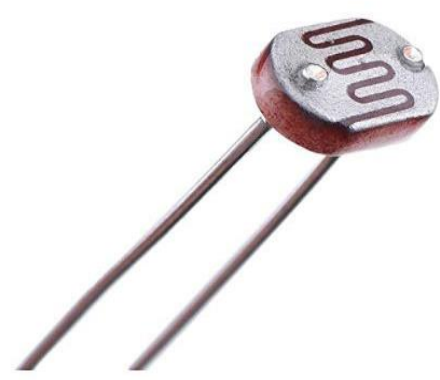

Fig 1: LDR sensor 


\section{B. Integrated circuit :}

An Integrated circuits (IC) is a semiconductor on which a thousands of micro resistors, capacitors, and transistors are fabricated. For automation we have used IC4093. The IC 4093 may not have complicated specifications. It consists of some fundamental blocks which can be configured according to personal preferences and used for numerous different applications. Externally the IC 4093 looks quite an ordinary dual in line type of IC. It consists of 14 pins and has four CMOS blocks internally embedded inside. These blocks are called gates, here these are termed NAND gates.

Understanding and using NAND gates of IC 4093 is simple and there's nothing complicated about these gates.

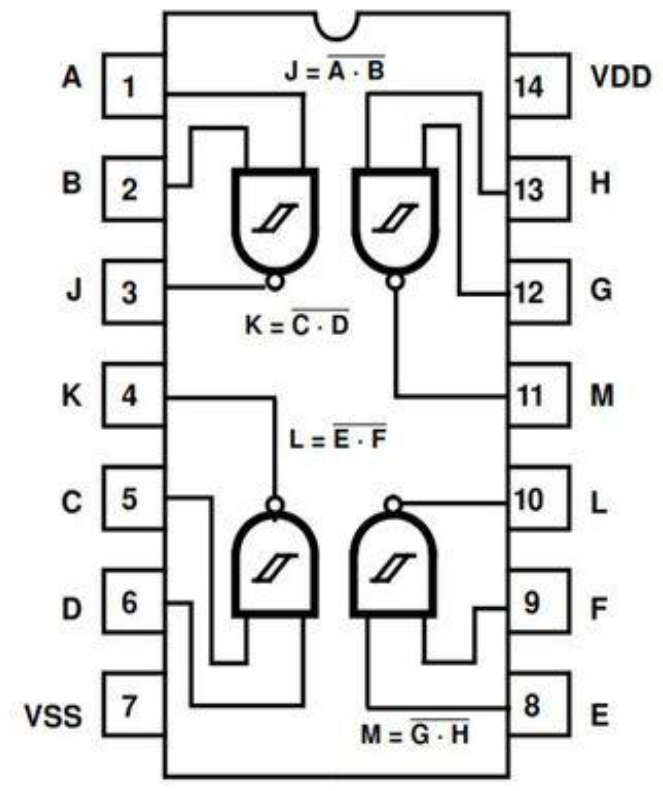

Fig 2: IC4093 Circuit diagram

\section{POWER RELAY:}

A power relay module is a device that uses an electromagnet to open or close a circuit when the input is correctly excited. We have used DOAT-3F-S-5VDC Power relay. Which is a sugar cube power relay. When you give DC supply to 2 of its terminals of electromagnet, switch is shifted from N/C position to N/O position. Now the $6 \mathrm{~V}$ relay is operated by giving a $6 \mathrm{~V}$ supply to the electromagnet while a $12 \mathrm{~V}$ relay has to be operated by giving a $12 \mathrm{~V}$ supply.

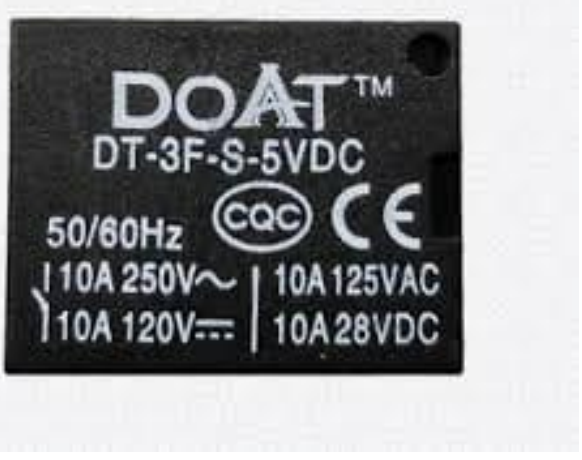

Fig 3: Power relay 


\section{DAY-LIGHT INTENSITY:}

Daylight Intensity is the combination of all direct and indirect sunlight during the daytime. This includes direct sunlight, diffuse sky radiation, and both of these reflected by Earth and terrestrial objects, like landforms and buildings. Sunlight scattered or reflected by astronomical objects is generally not considered daylight. Thus, daylight excludes moonlight, despite it being reflected indirect sunlight.

Table -1: Daylight Intensity

\begin{tabular}{|c|c|c|c|}
\hline Position & \multicolumn{1}{|c|}{ Sunrise } & Upward & Sunset \\
\hline $\begin{array}{c}\text { Maximum } \\
\text { (Lux) }\end{array}$ & 980 lux at $2.00 \mathrm{pm}$ & 970 lux at $11.00 \mathrm{am}$ & 950 lux at $12.00 \mathrm{pm}$ \\
\hline $\begin{array}{c}\text { Minimum } \\
\text { (lux) }\end{array}$ & 750 lux at $5.00 \mathrm{pm}$ & $350 \operatorname{lux}$ at $5.00 \mathrm{pm}$ & 830 lux at $5.00 \mathrm{pm}$ \\
\hline
\end{tabular}

\section{Graph:}

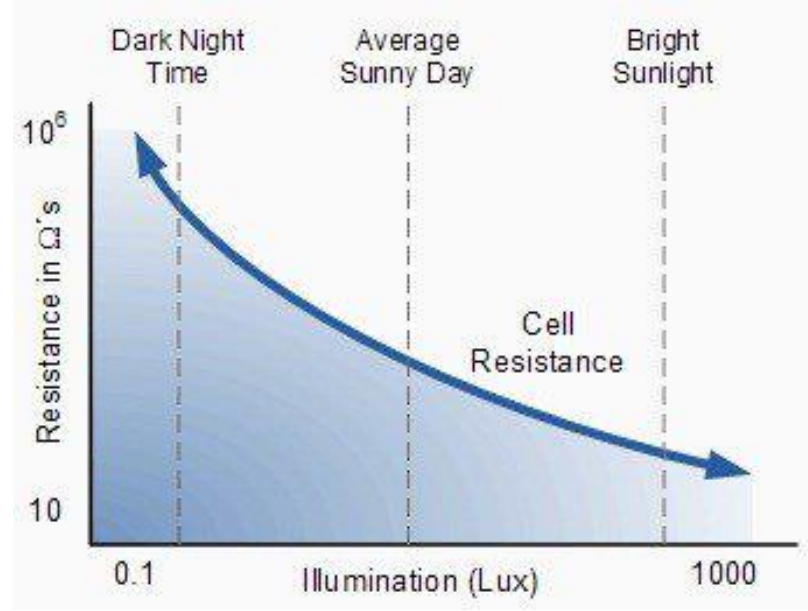

\section{HARDWARE CIRCUIT DIAGRAM :}

In our project we are mainly using LDR (light dependent resistors) which is a light intensity sensor and IC4093 to operate the power relay module. The power relay turn on and turn of the electric lights. The turning on and off of the lights are happened with respect to the intensity of the daylight.

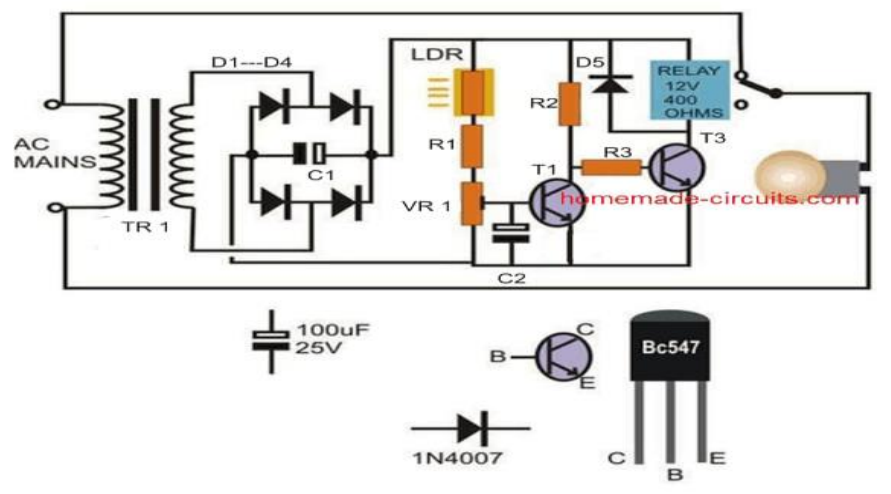

Fig 4: Circuit diagram of the project 


\section{FLOWCHART:}

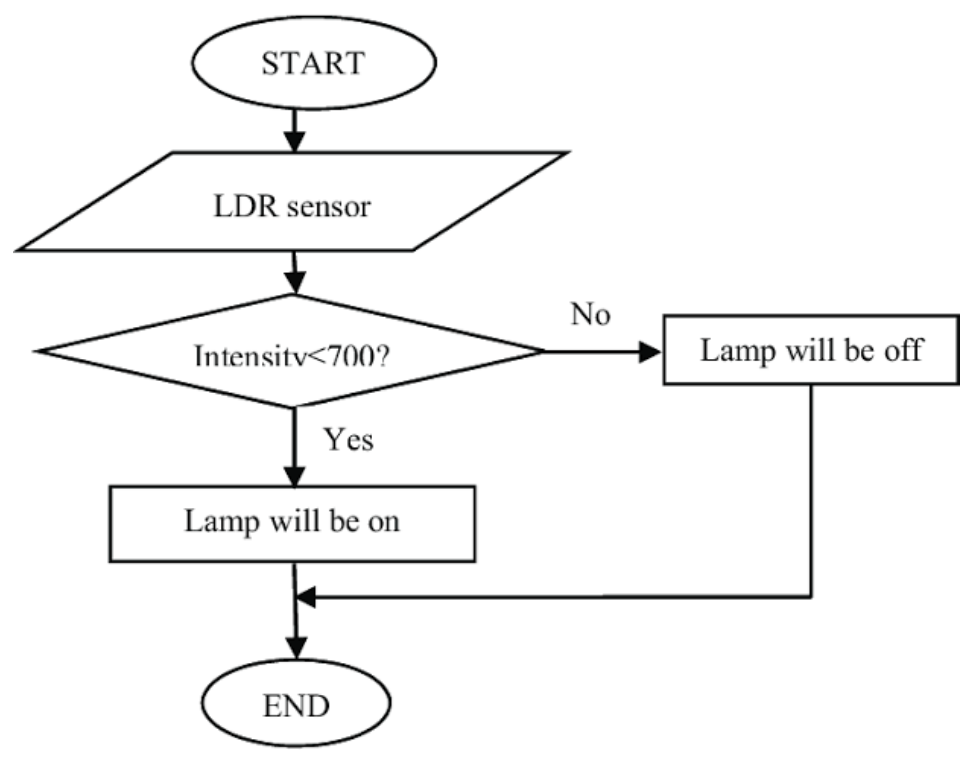

\section{CONCLUSION:}

From our project we conclude that we can save enormous amount of energy that is wasted daily. By our project the energy wasted can be saved and the carbon emission by the energy production is reduced. The man power used for operation is also reduced.

\section{FUTURE SCOPE:}

In future our projects can be further more developed by adding application of IOT and connecting it to the network and easily managed from a single control. Our project is having a good value because it can be applied in many places in future.

\section{REFERENCES:}

1. "Ultra-Low Power Integrated Circuit Design: Circuits, Systems, and Applications (Analog Circuits and Signal Processing)" by Nianxiong Nick Tan and Dongmei Li

2. F. Kausar, E. A. Eisa, and I. Bakhsh, "Intelligent Home Monitoring Using RSSI in Wireless Sensor Networks," International Journal of Computer Networks \& Communications, vol. 4, pp. 33-46, 2012 